\title{
Implications of Global Climate Changes on Horticultural Cropping Practices and Production in Developing Countries
}

\author{
Bruno Quebedeaux \\ Horticulture Department, University of Maryland, College Park, MD 20742-5611
}

\begin{abstract}
Global climate change from the increase in "greenhouse gases" is becoming a major scientific and political issue to international agriculture. There are various uncertainties and controversies surrounding the so-called "greenhouse effect" and the projected effect of global warming on agriculture in the United States and developing countries. This problem should not be neglected by horticulturists, and climate research should become a higher priority for horticultural scientists than it has been in the past. Recent reports and assessments suggest a significant climate change is very likely if emissions of "greenhouse gases" continue at currently projected rates. The atmospheric $\mathrm{CO}_{2}$ concentration has increased significantly and, based on the increased burning of fossil fuels and deforestation, will double to more than 600 ppm by the year 2050 . The atmospheric concentration of other "greenhouse gases" such as methane $\left(\mathrm{CH}_{4}\right)$, nitrous oxides $\left(\mathrm{N}_{2} \mathrm{O}\right)$, and chlorofluorocarbons (CFCs) is increasing at an even more-rapid rate and is predicted to alter agricultural productivity. Methane is produced in water-logged soils in rice fields and also in fossil fuel burning. Nitrous oxide, also produced by fossil fuel burning, is increased by denitrification, nitrification, and chemical $\mathrm{N}$ fertilizer uses. Global CFC concentrations have risen due to increased use of refrigerants and aerosol spray propellants. These major greenhouse gases also absorb in-
\end{abstract}

frared radiation and produce reactive molecules that are responsible for catalytically destroying the ozone layer. A decrease in the ozone layer will result in increased UV-B and greatly affect both plants and animals. Continued increases in these "greenhouse gases" will likely produce global climate changes in temperature and rainfall. Atmospheric scientists are predicting increasingly mild winters at high latitudes and drier climates at middle latitudes. Associated with these changes is a global sea level rise that would have a significant influence on low-elevation areas. Future agriculture on a national and world scale will be challenged. Global approaches and developments are needed to limit the increase in atmospheric $\mathrm{CO}_{2}, \mathrm{CH}_{4}$, $\mathrm{N}_{2} \mathrm{O}$, and CFC. Now is the time to understand the prospects for global climate changes and to explore strategies for mitigating their negative effects on current and future horticultural cropping practices and world crop productivity. Worldwide agricultural development need not be constrained by these climatic changes. New approaches and development strategies are needed. Contributors to this colloquium will attempt to examine the prospects and proposed developmental changes and to determine the implications for horticultural cropping practices in the United States and developing countries. 